\title{
A Brush with Research: Teaching Grounded Theory in the Art and Design Classroom
}

\author{
Mike Compton", Sean Barrett \\ Columbus College of Art and Design, USA
}

Copyright $(\mathcal{C} 2016$ by authors, all rights reserved. Authors agree that this article remains permanently open access under the terms of the Creative Commons Attribution License 4.0 International License

\begin{abstract}
Grounded Theory is a systematic approach to social research that allows for new concepts and theories to emerge from gathered data, as opposed to relying on either established theory or personal conjecture to interpret social processes. Although Grounded Theory is a well-known method within social science literature, it is relatively unknown in art and design literature, even though it is useful for developing social context and human empathy. In recent years, the model has gained relative credibility in many other disciplines, offering potential advantages for interdisciplinary scenarios. This paper provides a detailed review of Grounded Theory from an educational perspective, and then concludes with some proposed pedagogical methods for art and design based practices.
\end{abstract}

Keywords Grounded Theory, Artistic Research, Design Research, Social Research, Art and Design Education

\section{Introduction}

"I never made a painting as a work of art, it's all research."

- Pablo Picasso

This paper is about explorations in teaching Grounded Theory, a well-established method for social science research, to art and design college students. Context is added by referring to current philosophic and theoretical discourses of Grounded Theory, as well as growing literature on the role of teaching research in art and design education. In broader terms, this paper is for art and design educators interested in intersections of aesthetic training with epistemological training.

The global conversation on seeing artists and designers as researchers is rapidly generating interest, debate, and scholarship. While ostensibly artistic research and design research practitioners have somewhat separate requirements and aims, they share some essential similarities. Both artistic and design researchers respect deductive analytic ways of learning and producing knowledge, even while promoting inclusion of more inductive and adductive approaches (1-4). Conversely both artistic researchers and design researchers are interested in the junction between their respective methods and scientific method (2, 5-7). And finally, both artistic and design research remain controversial and contested in the academy, albeit increasingly less and less (8).

Of course, much of art and design is intrinsically a research practice already. Indeed, this paper acknowledges the experimental and innovative methods of artists and designers. It would be unproductive to subject art and design students to a kind of self-negation that only recognizes research prowess from other fields. By introducing Grounded Theory into arts education, the objective is not to become "dressed up in analogy to scientific research output criteria"(4). Rather the aim is to practice interdisciplinarity, wherein students are equipped to participate in a method that is recognized by other disciplines in the sciences and humanities. Grounded Theory provides artists and designers with a well-known evidence-based method for generating knowledge that is compatible with their personal creative processes.

For students interested in social or human centered issues, Grounded Theory is an especially helpful research tool simply because the potential for productive synergies between art and science may be most readily apparent in sociology (9-11). Yet, even though artists and designers have an established heritage of social concern and engagement, as both creators and critics of culture, they are curiously absent from the social research literature base. This is somewhat unfortunate, as shared interest in cultural and social issues is the basis for a common heritage with sociology. Indeed, "music, painting, poetry, the novel, and drama" intertwines both communities (10). For example, both artists and anthropologists, who are both capable of being auteurs, employ Realism in film and photography (12, 13). Critical Theory, an epistemological cornerstone of modern art, is also shared by many branches of social science including psychology, anthropology, sociolinguistics, and others. 
Expressing a commonality with sociology in his book, Design for the Real World: Human Ecology and Social Change, Victor Papanek lamented that "the genuine needs of man have often been neglected by the designer" (14). Likewise, Christopher Alexander was critical of any architect who was more concerned with how their buildings" looked in magazines then by the satisfaction people felt when using them" (15). Contemporary design has become a profession that attracts human centered researchers in the guise of business anthropologists and consumer psychologists, with aspirations of creating products and services that improve people's lives (16). Even fine art's Avant guard, having fallen from the heroic modernist ideal into apathetic commercialism, has been struggling to recover meaning through renewed commitments to social justice (17).

Of course, art and design have other dimensions besides the social and psychological. Nevertheless, even in cases where social concern is not in the foreground; Grounded Theory can teach useful skills and sensibilities for gathering and analyzing data in a systematic self-documenting fashion. These capabilities have perennial value to the artist and designer throughout their career. MIT associate professors Karl T. Ulrich and Steven D. Eppinger observed that for the professional designer, "... a structured methodology for gathering data from customers remains useful and can lower the inherent risk in developing a radically new product. Whether or not customers are able to fully articulate their latent needs, interaction with customers and the target market will help the development team develop a personal understanding of the users' environment and point of view. This information is always useful even if it does not result in the identification of every need the new product will address" (18). Design Methods expert Bruce Hanington states similarly, "Our work is about knowing how to structure the conversations we need to inform the best design solutions for the work we do.... Each provide an opportunity to structure conversations that can help us better understand and empathize with people..." (19).

Today's students are faced with the challenge of addressing diverse and multidisciplinary audiences. More than ever, art and design students must consider the role of research in their careers. Yet, it's expected that the burgeoning growth of artistic and design research can only come forth as a complex branching of ontological, epistemological, methodological and technical orientations. Against this background Grounded Theory's strength is that it can be a unifying approach to research that is adaptable for a variety of scenarios (20).

This paper is divided into six sections that attempt to show that Grounded Theory is a worthwhile subject for art and design students. The first section briefly outlines the relevance of social theory for today's art and design students. The second section provides some historical background behind Grounded Theory. The third section presents an overview of the Grounded Theory model in the context of art and design education. The fourth section proposes some particular approaches for teaching in the classroom. The fifth section discloses criticisms and challenges for Grounded Theory, and areas for future investigation. The sixth and concluding section considers the role of artistic and design research in an interdisciplinary context.

\section{Part 1: The Value of Studying Methods for Generating Social Theory in Art and Design Education}

A cursory review of design's professional literature suggests there is interest in borrowing the "devices" of social science, but not so much interest in the theoretical concerns behind the different tools. Andrew Blauvelt touched on this derivative tendency in design research when he reviewed an AIGA publication on design ethnography as, “... an introductory guidebook for practicing designers, of course, and therefore I shouldn't be surprised by the instrumentality of it all" (21). In similar fashion, Christopher Alexander once asked a hall of software developers if their interest in his pattern language was merely technical and, in effect, missing the larger social context. "I have no idea whether the search for something that helps human life is a formal part of what you are searching for. Or are you primarily searching for - what should I call it - good technical performance? This seems to me a very, very vital issue." For Alexander, a designer's attention to social theory was linked to the persistent question of whether they are more than technicians (22).

It's worth noting that Grounded Theory contributions can be useful and valid even when they don't make their way into the formal canons of higher learning. In fact, the Grounded Theory researcher doesn't necessarily need to be concerned with delivering a wholly original or ground breaking theory; only with generating a substantive or meaningful theory about a specific human or social behavior within a select population.

However, creating this theory is distinguished from the designer's strategy brief, which is concerned with the creation of a new product or service. This binary separation is of course a simplistic schema, but is helpful in protecting the goals and integrity of both disciplines. If research method dissolves into design method, the insights that are generated are likely to be little more than reified concepts and tropes. Along these lines, Jeanette Blomberg, in an article titled "Ethnographic Field Methods and Relation to Design" notes that some research scholars are wary of research projects claiming academic labels, while being used for commercial ends. For them, a designer may certainly use ethnographic methods, but can only legitimately use the label "Ethnography" when the end product is an ethnographic study, and not a new mobile device or a brand strategy (2325). 
The formation of both a grounded social theory and a design strategy is emergent, meaning that small observations and ideas can be gathered and organized into a concept that transcends the parts $(26,27)$. Social theory and design strategy remain separate emergent constructions, but both can help validate and inform one another in the design research process. Again, although we distinguish social theory from design strategy, this relationship is not like a linear or sequential chain of separate links. Rather, design is nested or intertwined within social concept, perhaps analogous to a DNA strand. We design in response to our interpersonal, as well as intra-personal dialogues about human or social processes, even using design experiments and tests as part of this dialogue. In this way, both theory and strategy emerge in parallel, not sequentially.

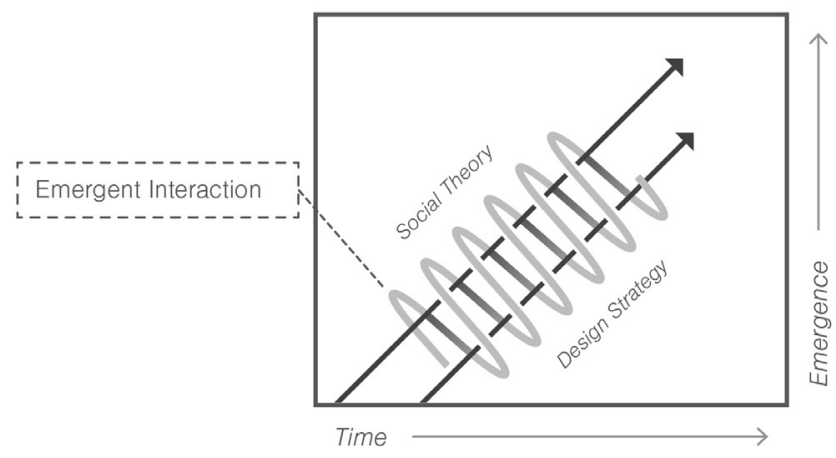

Figure 1. Overlapping Stages of Grounded Theory

The question arises whether artists and designers should be in the theory making business in the first place. Perhaps an equally critical question is how else can artists and designers proceed unless they hold to some model of social or human processes? Bloomberg notes that "Armed with knowledge of user work practices gained through direct observation of users at work, designers are in a much better position to accurately, and more fully, incorporate users' perspectives in the design..." (23). John Wettersten, a design director at IDEO Chicago echoes the point, "We are always designing for others" (28). Of course designers can always make themselves the focus of a study, engaging in a process of autoethnography (29). Nonetheless, most designers work in response to beliefs, whether consciously or not, about how people experience and act out their daily lives.

Even from a purely economic perspective, learning to conceptualize human and social processes is quickly becoming an essential design skill. During the last half century the U.S economy has moved from a goods manufacturing base to over $78 \%$ of the GDP corresponding to providing of services (30). Other western economies have made similar shifts. However, this is not a simple manufacturing and tertiary split, but an emerging mixture of smart-products and service experiences. This mixture can manifest as a "goods-services continuum," in which product are conceived as components in a larger service design, or as "product-services-systems," in which not only product and service are considered, but consumption and disposal experiences are also designed with sustainability in mind (31-33). Arguably, today's designers must contribute to a new seamless "experience economy" wherein competitive advantage is not achieved by designing better product features, but better "customer experiences." Grounded Theory offers the designer a systematic method for understanding the experiences of potential customers.

Differences in market philosophies between designers and fine artists continue to be debated and disputed, but Design Research, Artistic Research and Arts-Based Research practitioners share a growing mutual interest in having social impact. While designers and artists work across a wide intellectual spectrum, both are recognizing social concept is a vital part of their practice. New interest among artists and designers in conducting and publishing primary research signifies a transition from reactionary ideology towards generating responsive social theory (34). If artist and design students are going to publish original social research, whether in the the academy or industry, they will benefit from using a method conceived and proven for this end.

\section{Part 2: History and Purpose of Grounded Theory}

Sociologists Barney Glaser and Anselm Strauss published The Discovery of Grounded Theory in 1967 as a data-grounded method for providing social researchers with academic freedom to generate theory. The two authors felt that young sociologists coming into their field in the 1960's were limited to only verifying the canon of "Grand Theory" rather than making new contributions (35). Rooted in a critique of theoretical dogma, Grounded Theory should appeal to artists and designers who want similar latitude to uncover fresh perspectives, rather than being confined by histories influential art and design movements, or market trends. Sharing this commitment towards originality in art, as well as research, Arts-based Research (ABR) is also concerned with theory building (36).

While Glaser and Strauss's collaborated on the original introduction of Grounded Theory, going forward they began to disagree on some aspects of the method. The original book described data gathering and analysis as inductive and emergent, but Strauss (with Juliet Corbin) added structures and formulas to the data process $(37,38)$. In response Glaser complained that in adding to the original formula, Strauss had in fact created a new method - a "forced conceptual description" (38, pg. 5). Udo Kelle characterized this "emergence vs forcing" debate as a "crucial problem" for practitioners of Grounded Theory to consider (40). Of specific debate was Strauss' use of a predetermined coding-paradigm that would structure and code data as it was researched, as opposed to Glaser's open coding system that develops from the data as it is gathered, organized and analyzed into theme-based categories. 
This controversy between Glaser and Strauss should be noted by the student researcher exploring Grounded Theory literature on their own. The persistent confusion seems to be the difference between a conceptual verses descriptive analysis of data. Glaser has been sharply critical of the tendency among novice Grounded Theory researchers to default to "standard qualitative research analysis." In fact, he has written extensively on the difference between concept and data description (41). Glaser wants the Grounded Theory researcher to develop their preconscious talent for allowing data to emerge into concepts that have "grab." Using one's own preconscious imagination as a research instrument may come as a surprise to design students who might be suffering from what Glaser calls "data worry."

Indeed, many student researchers are uncomfortable with the trust Grounded Theory affords them (42). For this reason, Glaser suggests that Grounded Theory is may be more suitable for graduate or doctoral students. As a consolation, Glaser is quick to remind uneasy researchers that there are a myriad of other options for qualitative data analysis (QDA) besides Grounded Theory. He argues that if a researcher requires extensive sampling, systematic data and records keeping, objective descriptive analysis, and concurrence with existing theories, then they can use any one of the other QDA tools available; if they want to generate an insight or concept about how a substantive portion of the social world operates, then use Grounded Theory.

The essential differences between Glaser and Strauss aside, both streams of Grounded Theory seek to generate verifiable theory through an evidence-based approach, linking conclusions as directly as possible to gather data evidence (35). The ideas and insights produced during a Grounded Theory study must be constantly compared with new data, not to restrict researchers, but to focus emerging concepts.

This conceptual freedom and originality inherent to Grounded Theory can't be stressed enough to students. Novice student researchers often believe their primary aim is to describe their data. As has been stated, Grounded Theory seeks to generate original concepts that speak to how people solve their unique conflicts and problems - not reports of probabilistic typologies or statistics.

Another hindrance to conceptual freedom can come from being too committed to a particular school of thought. Students who are well read in cultural, sociological, or even philosophical literature may unwittingly impose outside ideas on their data. For instance, Grounded Theory's tolerance for subjective interpretations suggests a natural compatibility with symbolic interactionism, social constructionism, or other schools that seek to understand actual lived human experience (43). However, Grounded Theory should be regarded as autonomous, rather than synonymous with any established social theory. Although it inherently excels at understanding experiences within a substantive context, Grounded Theory should not be conflated with formal constructionist or constructivist epistemologies. This commitment to simply understand human actions and conversations is compatible with Thomas Barone's assertion that Arts-Based Research complements the kinds of sociology research processes in which "the individual characteristics of the human being got abstracted out of reality" (44).

\section{Part 3: An Overview of Teaching Grounded Theory}

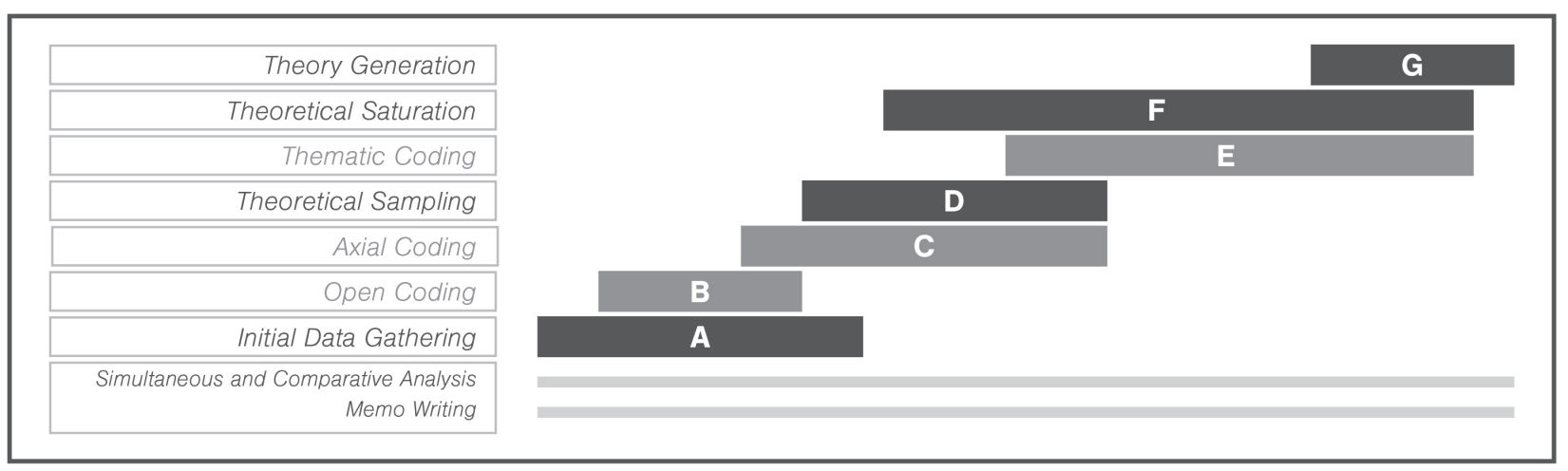

Figure 2. Overlapping Stages of Grounded Theory 
This section reviews the basic overlapping stages of Grounded Theory within the context of art and design college education. Most of the examples included are from the College of Art and Design in Columbus Ohio, with participation from other schools. The goal of this section is to not just offer a technical exposition of Grounded Theory itself, but to also provide glimpses of the research methodology in various group learning scenarios. It is worth noting that group exercises have inherently different dynamics then individual research projects. This section concludes with a review of student outcomes.

\section{Designing the Research}

In planning and designing their research, the student design team considers several key questions as outlined by Grounded Theory teacher and author Kathy Charmaz.

- What is this a study of? Are we trying to study or understand (42)?

- From whose point of view will we be looking (45)?

- What behaviors and activities will we be interested in (46)?

- What forms and varieties of data will we be gathering (47)?

- What latent patterns and insights are in the data (45)?

Beginning our planning with the agreement that we are using Grounded Theory, it is helpful to begin the planning process with a simple list of Grounded Theory's essential attributes, which are: open-minded observation of social reality, qualitative and quantitative data collection accompanied with constant comparative analysis, and a commitment to systematic documentation that allows conclusions to be directly linked to evidence (35). Most importantly, as noted in the introduction, Grounded Theory allows the researcher to offer original concepts that transcend mere data description (48, p. 148).

A Note on Intuitional Review Boards within Art and Design Education

While outside of the focus of this paper, a brief note about Institutional Review Boards is perhaps in order when discussing the planning of research. Art and Design colleges, especially private institutions not situated within liberal arts communities, generally do not consider they research institutions per se, and typically don't have Institutional Review Boards. However, as these schools move deeper into social innovation, human centered design, and design thinking rooted in human empathy, the role of the IRB in design will become increasingly compelling. Indeed, even business and marketing research involving human subjects merits oversight. While much student design research involving human subjects could probably be classified as "exempt" by an IRB, when a student research project requires participants to share personal information, oversight is part of sound research pedagogy. If an art and design school is unable to form an internal IRB, they can seek training and accountability with an IRB at a neighboring college.

\section{Sampling Techniques for Grounded Theory}

Sampling is how researchers determine their units of study, such as individuals, couples, households, or organizations, and where and how to find them. For example, student researchers at the Columbus College of Art and Design interested in individual contemporary gardening lifestyles felt that a good place to begin would be the retail centers that attract a variety of customers. This project received support from a national trade association for the horticulture industry, enabling students to visit over 50 garden centers in six different cities. In a smaller scale example students worked with a local non-profit cancer research organization that was interested in building a national brand; the students didn't want to rely on the organization's understanding of their support base, choosing instead to use Grounded Theory to build their own understanding.

Subjectively determining which subjects to begin with in both of these examples, the students used techniques formally known as purposeful sampling, judgmental, or subjective sampling. Far from random selections, these are heuristic or inferential approaches that deferred to either the researcher's preference, or to those participants who are most likely to be cooperative. For instance, in the study on horticulture, Independent garden retailers were selected over national chains because the researchers believed independent owners would be more open to on-site visits, and their customers would include a wider range of novices to experts.

Even so it is helpful to gain access through referrals whenever possible. For example, faculty can contact trade associations to explain the goals of the research; trade associations and non-profits are likely to understand the value of fresh research, and can help make introductions and give the project credibility. In one case, faculty asked retail storeowners to refer possible customer participants who might want to be a part of the research project. Asking participants to refer additional participants is another inductive sampling technique known as snowball sampling.

All of these types of initial approaches to sample selection are often referred to as non-probability techniques, where the units of sampling are left up to the judgment of the researcher. The exploratory nature of the early stages of Grounded Theory process often begins with these non-probability sampling techniques. Of course, the sampling population and frames for reaching new populations can evolve as the study progresses.

\section{A) "All is Data:" The Gathering Process}

In Grounded Theory, "all is data" (49). One aspect that artists and design students most enjoy about Grounded Theory is that the original framework produced by Glaser and Strauss recognizes various forms of multimedia as data (34). Audio-visual materials and other documents are just as valid as qualitative interviews and observations (50). Our 
student researchers used video and DSLR cameras, as well as formatted questionnaires, and worksheets to aid in data collection. Each student kept a notebook for descriptive field notes, as well as personal reflective thoughts known as memos. Text transcripts, although not necessary for Grounded Theory, were made from the audio recordings for later analysis. Thus all the various forms of data the students generated, ranging from transcripts, to field notes and memos, to audio-visual records of physical activity such as video, photography, and even their sketches, proved useful for analysis (45).

Both the artistic and sociological study of contemporary culture will invariably encounter logos, signs, photographs, videos, digital image screens of all sizes, graffiti, and countless other visual artifacts (51). Art students should be well prepared to analyze this semiotic inventory, educated as they are in the canon of cultural criticism that includes Roland Barthes, John Bergers, Anne D'Alleva, Erwin Panofsky, and others. Beyond visual media, audio can also be the subject of analysis. John Cage observed that true silence is impossibility (52), and so every audio environment, live or recorded, can contain meaningful or useful data. What kind of music is playing? Are there children laughing, or urban sounds of car horns or construction? (50). Even the frequency of mobile device chirps and beeps can reveal insights into the lives of participants. The clues and patterns in audio are compared and contrasted to other forms of data gathered during the project.
Lastly, the artistic or design researcher can "interview" using non-verbal techniques. Through image or photo elicitation the researcher can ask a participant to interpret the contents of pictures (9). Another creative research technique is to equip participants with their own cameras and ask them to shoot pictures along specific lines of inquiry (53). For instance, in a study of how 20-30 year old participants were given two house plants, a journal, and disposable cameras, for self-documentation for a two-week period. These types of elicitation methods can yield deep insights into hidden or unspoken beliefs and attitudes (19).

\section{Data Organization and Management}

It's worth noting that collecting data in the field can be mentally and physically demanding as researchers are striving to observe and write down as many of their initial thoughts as possible. As a result, student researchers often see returning from the field as an opportunity for "downtime," rather than attending to other important research related tasks. Daily attention to data archiving and management optimizes the field experience. A good organization plan can be embodied in a digital folder system that anticipates every kind of media and method. The most common kind of digital data is often text-based files such as Microsoft Word or Apple Pages formats (54). There are a number of computer-assisted qualitative research platforms that can assist with data management and retrieval, although these are not necessary for Grounded Theory analysis (55).

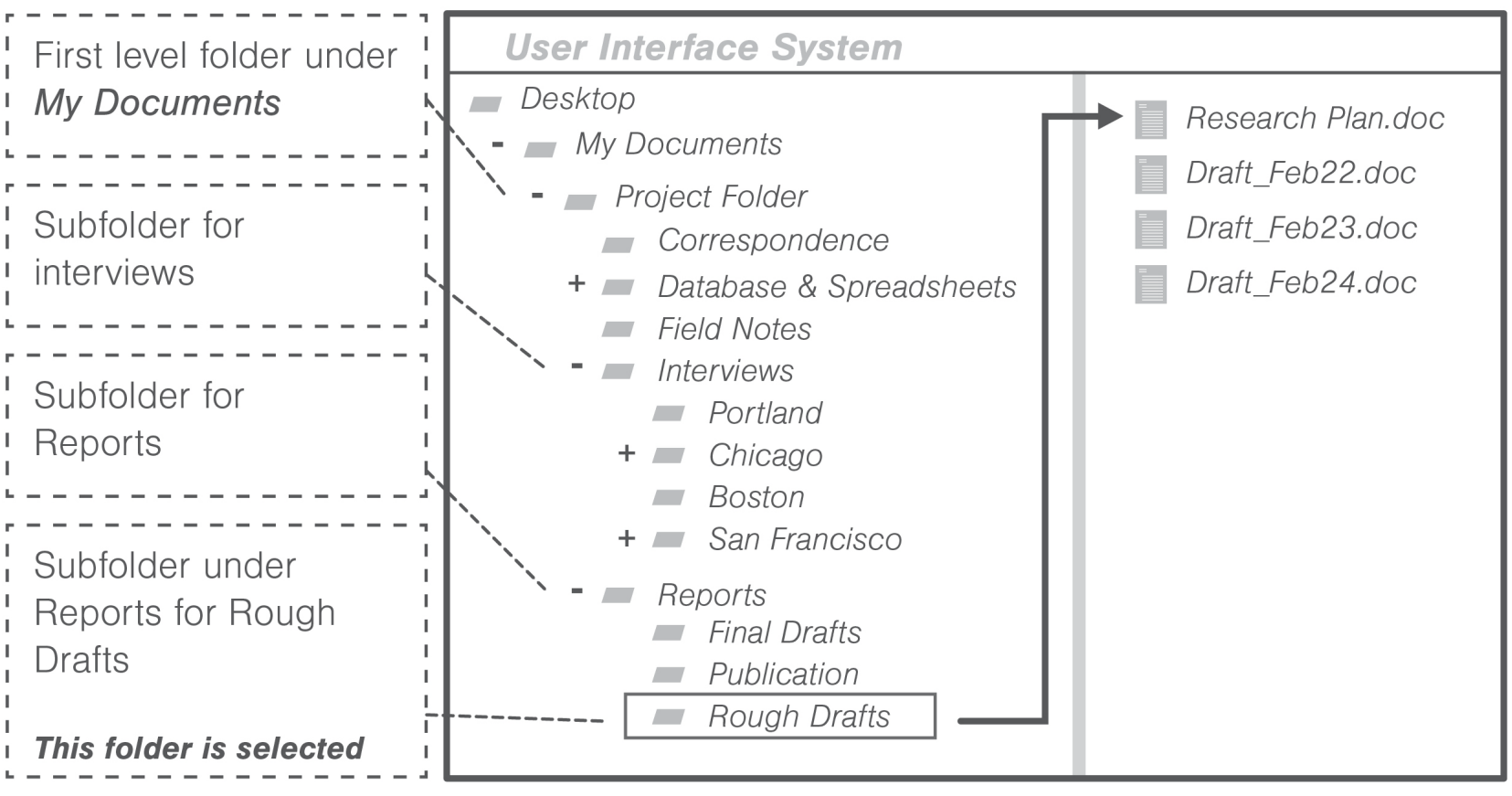

Figure 3. Computer Data Organization and Management Folder Structure 


\section{The Process of Constant Comparison}

Because Grounded Theory is an inductive process it follows that researchers won't know all of their data requirements until later in the study. Researchers use their observations to guide ongoing gathering efforts and then compare subsequent data to earlier collections. For the students, this meant reflecting early on what they've learned from their first on-site visits, interviews, and diary studies, in order to form their ideas and categories. Categories of ideas then became areas of interest for determining next steps, such as whether the students are talking to the right people about the right topics, or if they need to delimit their population and focus. This process of using initial categories to determine new lines of inquiry can also work in reverse by using newer data to refine and redefine previously established categories. Throughout the research project, the Grounded Theorist uses this constant comparison approach to make sure the investigation is going in a productive direction, and to decide if and when adjustments are needed. Eventually this method allows the researcher to arrive at a single category to become "the central phenomenon of interest" (50).

\section{The Practice of Memo Writing}

In addition to taking field notes, the student researchers were encouraged to keep a distinct and separate discipline known as memo writing. Memos are reflective and imaginative thoughts of the researcher, and should not be mixed with field notes, which are more faithful descriptions of observations (56, p. 136). For students, keeping two different types of notebooks or journals was a challenge.

Field notes are more akin to the kinds of notebooks students should have open during classroom lectures. Memo writing can be more easily compared to a creative journal, which is a practice that is familiar to many artists and designers. Another way to see the difference is that field notes are a form of data, while memos are a form of analysis. Memoing allows the researcher to freely capture their daily reflections and feelings about their experiences throughout the research project. Memos can be anything from loosely scribbled ideas, to cohesive and refined text, to drawings. While keeping a daily regiment is fine, memos are best when they are captured frequently and spontaneously $(56$, p. 6). It is advisable that researchers take time to memo before any group retrospective that could influence or dilute their own thoughts. (The design students that traveled to visit garden centers would often end their day in the field at a restaurant where they invariably engaged in reflective conversation.) Daily memoing helps the researcher trace their journey of discovery and allows them to construct more advanced thoughts. Memos are not meant for critique or for sharing, but for self-dialogue and for tracking the evolution of personal thinking. A healthy memoing habit helps build the intellectual fluency and content needed to write actual theory later in the project.

\section{The Art of Coding}

Central to the practice of Grounded Theory is the practice of coding, which is assigning interpretive descriptions or codes to carefully reviewed data. Art and design students who are familiar with semiotics and social symbolism already have a basic understanding of the role codes play in interpreting and naming human behavior. Design students may also think of codes as possible insights into design solutions. In fact, design students who are familiar with affinity mapping will already have a basic understanding of the revealing and organizing power of coding. Furthermore, coding and memo writing strategies of Grounded Theory have influenced other forms of analysis (57), so that time spent learning good coding skills can benefit other research methods.

Codes can be as simple as notes jotted in the margins of printed transcripts. Students, often operating under compressed schedules, may find that writing out codes on printed transcripts is a practical technique. However, researchers who intend to publish their social theories academically should keep clear documentation of their coding methods and systems. Furthermore, as the sample sizes and data sets grow in size and complexity, researchers can rely upon computer-assistance. (For the time being, computers only help with data management, not with conceptualization.)

Coding is a continuous process throughout the Grounded Theory project. The analyst uses codes as experiments with interpretations of various incidences and indicators, so that relationships and patterns can emerge. Patterns are the only true indication of categories, so students will need to avoid the temptation to form conjectures from single incidences. The evolution of codes their form emergent documentation, whereby individual and unrelated codes begin to reveal patterns, then categories, until the central theory emerges.

A parallel exists here to formal art critique where the first step is simply describing what is happening, using purely observational information picked up, initiated from a non-judgmental approach. For example, open coding is the creation of generic codes derived from the data pool, intentionally avoiding conclusions - researchers highlight anything and everything, observing to the best of their ability. Pure, physical, phenomena is systematically identified. Like the art criticism, the coding process continues on through stages of description, analysis, interpretation, and conceptualization. 


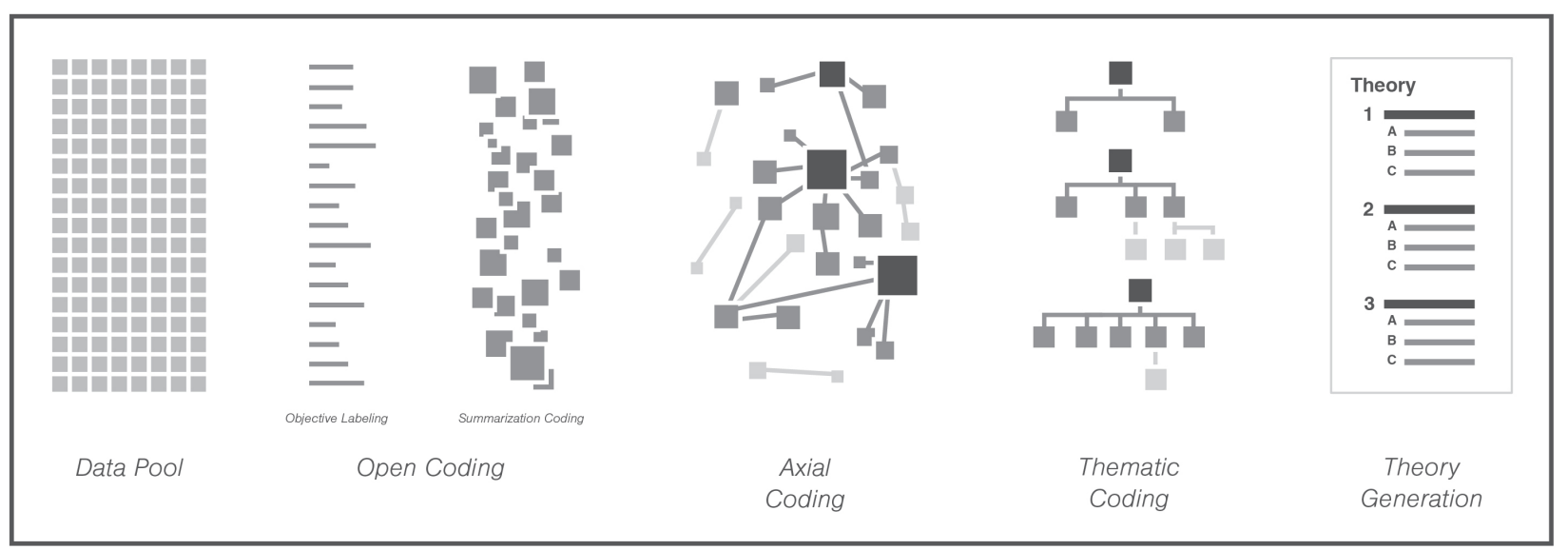

Figure 4. Grounded Theory Coding Phases

\section{B) Open Coding}

Open Coding is the initial coding process in the Grounded Theory framework, and therefore can be the most eclectic and divergent phase. The first goal of open coding is to focus on self-revealing phenomena, not to attempt to guess at hidden meaning in the data. Aptly named "open," the lack of a coherent direction can be unsettling to student researchers, who often want to look for core variables in the data as quickly as possible. There are two strategies one can apply to overcome these hasty instincts. The first is to intentionally write eclectic or divergent codes. In this way, a student has "permission" to defy their instincts to prematurely decide on the meaning of their research (58). The second is to deliberately code every line in a transcript, known as line by line coding, to slow down the rush for "answers." Line by line coding also allows the researcher to decide how dense their coding should be for each transcript (41).

\section{C) Axial Coding}

An interim step of coding between open and thematic coding, axial coding was a later and controversial addition to Grounded Theory by Anselm Strauss independent of his original collaboration with Glaser. Axial Coding attempts to develop "objective" relationships between open codes and the conceptual themes that are subsequently codified. This extra step may help the researcher ease into analysis, but it may also cause researchers to timidly lapse into cautious description of data, shying away from conceptualization or interpretation. As an example from our horticulture retail study, retailers were worried about the lack of 20-35 year old shoppers in their stores. Axial codes could collect various descriptions of Millennial gardening related activity, but this assortment may never point to a clear compelling concept about their behavior.

Strauss and Corbin regarded axial codes as an essential discipline, while Glaser remains sharply critical of axial codes for their tendency to drag the researcher into covering too many bases (46). Nevertheless many researchers who identify themselves as Grounded Theory practitioners use axial codes as a way of adding descriptive connections back to their original data. It is our intent to include axial codes only as part of an introduction to Grounded Theory literature. Readers will need to decide for themselves whether axial codes are useful or a hindrance to their conceptual process.

\section{D) Theoretical Sampling}

While comparing and connecting the codes, suspicions about key insights and concepts emerge that can only be validated by redirecting and/or expanding the study population and sampling frame to allow for new participants, this theoretical sensitivity should determine and guide subsequent data gathering in an approach known as Theoretical Sampling (41, p. 37). In practical terms for students, strategies for theoretical sampling came out of group discussions about important insights that interested them. Refining the sample criteria helped realign the project to more accurately reflect and ultimately strengthen the students developing theoretical sensitivity. For example, after identifying that many Millennials were more interested in growing food then flowers, the student researchers wanted to expand their next data collection efforts to include community gardens.

The practice of theoretical sampling in the classroom encountered two potential pitfalls. Firstly, because theoretical sampling implies a meandering sampling strategy, Grounded Theory research proposals must disclose to institutional review boards, as well as other stakeholders, that there may be no way of fully anticipating all of the participants the study will require. For example, in one case a project sponsor, (a non-profit organization,) was understandably unwilling to provide access to an unexpected and potentially key sampling frame: their supporter list!

Secondly, theoretical sampling still needs delimiting. The focus should be on those populations that can help conceptual analysis and formation, rather than exploring every possible variable that comes to mind. The Grounded Theory project is looking for concepts that emerges from 
data, and is not concerned with uncovering and synthesizing every negative case or creating comprehensive typologies of all the variations encountered (59). As with other aspects of Grounded Theory, many students are surprised by the conceptual trust afforded to them by Theoretical Sampling.

\section{E) Thematic Coding}

As stated above, many design students may already be familiar with various idea sorting techniques such as affinity diagramming or picture sorting. These techniques can be useful in helping students understand how Grounded Theory coding enables conceptualization. As the students gained a broader and more holistic understanding of the nature of their assorted codes, they naturally began noticing major themes. Themes can serve the design process by functioning as key design insights. Themes can also later become "pillars of theory" for students who are interested in writing up their research findings. We found that some design students are pleasantly surprised that there may be an audience for their research apart from their design outputs. Their ability to offer firsthand accounting of social or human processes, demonstrating expertise in a particular behavioral or cultural area, can become part of their identity as knowledge professionals.

Thematic Codes can be used to group different semantic or linguistic incidences into shared conceptual categories, which in large sets can be counted and weighted like quantitative indexes. For instance, in the horticulture study there were a variety of attitudes towards taking care of plants; Some subjects expressed a sense of guilt over "killing their plants," others felt that plants were "mysterious", and still others wanted to know why retailed plants didn't "come with warranties like other products." All of these incidences could be coded and categorized into shared themes such as "lacking in confidence" or "avoiding failure." This allows more advanced Grounded Theory researchers to build indexes of both qualitative and quantitative data. These categories can ultimately point to a core variable, which in turn can become an integrated concept of a need that design can respond to.

\section{F) Theoretical Saturation and Confidence}

In addition to carrying preconceived conclusions into their research, novice researchers often have an inverse struggle in narrowing the focus of their research. In order to build a theory, students of Grounded Theory will need to decide which of their recently formed categories the final focus of their project is. Once student researchers learn how and when to delimit their focus, they eventually come to a place where their fieldwork is not produced any new insights. The themes, or "pillars of theory," have reached a general level of stability. Regardless of a researcher's experience, this stability is never absolute. For instance, many research subjects shared a myriad of unique stories about why they lack confident about growing plants. Consider again, the participant stories in the horticulture study; their stories became independent indicators that emerged into an indexed theme. One such theme is how, for many of the participants, plants are a frustrating and baffling challenge. Theoretical saturation can be achieved around this theme, without covering and describing every other type of feeling and experience plant growers have.

\section{The Literature Review}

Up until now, the students were encouraged to avoid looking for answers or conclusions in books and papers. Glaser addressed the point directly in a round-table discussion with doctoral candidates, saying "Don't worry. The literature ain't going anywhere" (60)! When it comes time to review the literature they find several similarities and confirmations with their own findings and conclusions. For instance, the students discovered a link between early home ownership and gardening; younger participants were interested in plants for food or ecological purposes, as opposed to older gardeners who tended to enjoy plants as a pastime for home beautification. Upon subsequent review, secondary surveys testified that "Millennials" and "Baby Boomers" generally have different attitudes towards home ownership, showing how a previously published demographic study could apply to a current study.

\section{G) The Generation of Substantive Theory}

The ultimate goal of Grounded Theory is to generate a substantive theory that is grounded in the verifiable data from an empirical study of a particular group of people. A substantive theory is attempting to conceptualize only the people observed, not inferring a universal theory for the broader sociological canon. A substantive theory is contrasted against formal theory, requires much denser data gathering. Substantive theory is the researchers' perceived "truth" until it can be published and verified by other researchers. However, it is logical, well documented, and can stand up to evaluation. This difference between substantive and formal theory can be of some comfort to the student researcher who may doubt the worth of their own "science" This assurance can open the door for the novice aspiring researcher to consider writing and submitting their research for review.

\section{Publishing and Presentation}

One of the differences between academic research and commercial design research is in how the work is presented. There is also the difference between basic research, which increases public knowledge, and therefore must be published publicly, as opposed to action research, which is undertaken for a specific organizational goal and is not intended for public viewing. Students can learn logical and conceptual flow by studying the structure of well-written Grounded Theory papers. However, when presenting insights and recommendations to a project sponsor or "client," the students can use all of the media skills they have at their disposal.

Author Kim Erwin notes that communicating facts and insights are two separate problems. While facts can be 
shared with papers and power point presentations, insights are better served though shared experiences and stories, interactive presentations, and workshops. Researchers should consider how to design experiences that can inspire multiple stakeholders to take action, and then deliver the analysis and findings through theater (61). In the case of one presentation, students arranged for sponsors to do some original analysis exercises in a workshop. Then students compared their own conclusions with the ones the sponsors drew; in this way the sponsors could better understand the logic behind the insights.

While the commercial design researcher may not intend to publish their social research, it can be helpful for them to learn from structures of good academic writing such as thesis, method, analysis, literature review, analysis and conclusions. The logical flow of these proven reporting formulas can be translated into an effective client presentation.

\section{Part 4: Approaches for Teaching Grounded Theory in Art and Design Education}

This section outlines various aspects and lessons learned from experiments with Grounded Theory in the classroom and fieldwork. The first part of this section discusses some compatibility with existing art and design education. The second part of this section details some of our curriculum design ideas for teaching Grounded Theory to art and design students. The third and final part of this section reviews some of the positive outcomes for art and design students as a result of practicing Grounded Theory. As there is already literature on teaching Grounded Theory in the classroom, this section will review just a few teaching methods used in the specific context of art and design education.

\section{Connecting Grounded Theory to Art and Design Methods}

Francis Huehls, a professor at Purdue University observed that "Grounded Theory can be effectively introduced in a survey course through a combination of lecture/demonstration and simulation" (62). Accordingly, we found combining Grounded Theory training within existing project based learning to be the most effective as well. New ideas are better apprehended when connect to familiar ideas (63). An active project provides a context that makes the value and potential of Grounded Theory more readily apparent.

As previously discussed, many art and design schools presently teach and practice research inspired design methodologies such as Human Centered Design, User Centered Design, and Design Thinking. Introducing Grounded Theory as a means of providing data into these models effectively builds on ideas the student may already be familiar with.

A tangible example is Agile Methodology (64), which breaks up large complex problems into small quick iterations that are not only testable, but also informative to the larger project. Many students concerned with software related design focuses such as user interface (UI) and human computer interface (HCI) are likely to be familiar with agile, an iterative emergent approach to software development that seeks to understand people's needs and behavior prior to committing to technical solutions (65). Both Agile and Grounded Theory share a suspension of assumptions and willingness to enter into a project not knowing the outcome. Agile Methodology's emphasis on constant testing also parallels Grounded Theory's constant comparison.

Another popular iterative design approach is Design Thinking, which is committed to designing for people's needs, rather than our own preferred problem solving. Grounded Theory research may be used within Design Thinking as a method for defining empathy for a particular project $(66$, p. 28).

A variation of design thinking is participative design, or participative-action-research (PAR), in which the stakeholders impacted by a design project are invited to join the design process (67). Such an approach is not only iterative but it is also co-creative, helping align design objectives with needs of people. The empirical nature of this kind of human-centered design often borrows from social science methods of inquiry such as ethnography and recorded observation.

Agile Methodology, Design Thinking, and participative design are just three examples of iterative human centered design processes that should be familiar to designers. In fact, there are countless methods (68). being taught in art and design schools today, that could prove to be surprising compatible with the Grounded Theory model. Combining these different methods can not only accelerate understanding, but the intersections can lead to new and exciting approaches in their own right.

Coding Workshops and Workbooks

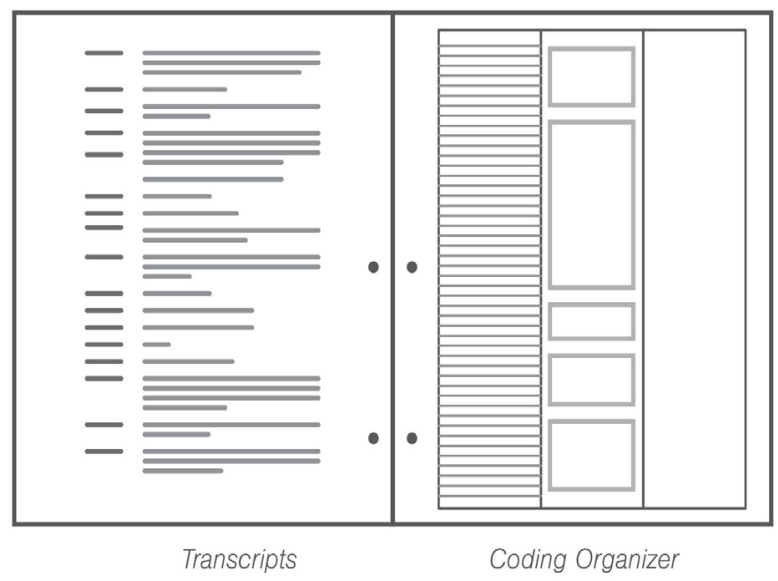

Figure 5. Layout of Workbook Exercise Showing Transcripts and Organizer for Practicing Coding

Coding workshops with printed workbooks are one of the more successful methods we used to help students grow in 
their Grounded Theory confidence. The workshops followed a simple research case that is also narrated through a power point presentation. After a brief introduction to the story, each student was given a pencil and a workbook that contained transcripts of related interviews. The workbook contained six different guided exercises for practicing various kinds and styles of coding. The first exercise demonstrated "In Vivo" coding, which is simply spotting and copying words or phrases from the transcripts that seem significant. In another exercise the students practiced looking in the text for incidences where participants reveal their decision making processes. These short and diverse exercises were intended to demonstrate the accessibility of "doing" Grounded Theory. By letting the students experience quick successes as data analysts, we were seeking to prevent "paralysis by orthodoxy" (69).

The workshops can be facilitated in person or through platforms like Skype or Google Hangout. Once the workbooks are transferred, printed, and provided to the students, the lecture and facilitation can be given remotely. In this way we've been able to share these coding exercises with several college classrooms around the world. As stated before, coding is not a method exclusive to Grounded Theory, and so the workbooks can have broader qualitative applications.

\section{Insight Cards}

Once a study has generated open and thematic codes, a design team has plenty of "insights" to inform their creative process. In one project, a couple of students printed these coded insights onto card stock, cut them out, and distributed them as card decks to design team members. This tool was especially useful for sharing insights with students who were not able to participate in the fieldwork. In the hands of creative people, these cards helped generate additional codes with a stronger relevance to the design goals.

The insight cards were used in several enterprising ways; one familiar example was the practice of affinity sorting and diagramming exercises (70). Physically connecting and clustering isolate cards into meaningful groups, affinity diagrams may be the clearest visual analog of the category building within Grounded Theory. Sorting is a basic human instinct, and yet it is an effective method for analyzing large sets of ideas and generating both theory and actionable design strategy (68). The process involves putting the cards into groups according to their perceived affinities, and then experimenting with new categories using different relationship criteria. Focus group expert Richard A. Krueger suggests that different colors of card stock can be used to discriminate the different sample participants interspersed throughout the categories (71). The cards can be assembled into categories on walls, long-tables or even on the floor. Students can lay large sheets of paper or poster board out to demarcate categories. Or the teacher can provide the categories as a way of providing structure to first time researchers. Once the cut-out codes are then taped secure, the sheets can be hung up for further reflection.

\section{Writing as an Art and Design Pedagogy}

Admittedly, one of our unspoken aspirations for introducing Grounded Theory in the art and design classroom was to inspire more writing. A persistent fallacy surrounding visually literate students is that they are somehow less literate in other areas. Artists hear adages like "your work should speak for itself," or "you are judged by your work," implying that artists and designers somehow have less need for that most basic of human social skills spoken and written language! "Designers, Meet the Word" is the tagline on the back of Steven Keller's recent book Writing and Research for Graphic Designers. The book's foreword is a veritable call to arms against "a certain slander" that artists and designers are not interested in reading or writing. Heller asserts that "Today, designers must master the visual and verbal...reading and writing and, more than ever, research (a third imperative skill), are the designers essential three R's" (72).

An initial and encouraging finding from our Grounded Theory explorations has been that a structured research process helps in the development of critical thinking and writing processes as well. Students learned that the disciplines of systematic and constant writing, note taking, and jotting of thoughts led to improved ability to articulate concepts. Furthermore, for those that were diligent in their daily writing throughout the research process, their final writing process was not so burdensome. Significantly, a few students discovered that they enjoyed the writing process.

\section{Part 5: Criticisms and Challenges}

Although Grounded Theory is one of the most popular and influential research methods in social sciences, it will admittedly face challenges in art and design education. Firstly, the model is not without its critics (73). The interpretive or subjective nature of Grounded Theory can undermine its goal of providing a verifiable methodology; for instance, coding can be a very time-intensive practice, with a single piece of data capable of yielding more than one valid code (74). Indeed, democratic access to Grounded Theory occasionally attracts suspicion as to whether any newly generated theory can be certified as "real" or "made up." Others point out that Grounded Theory is easy to "claim" as a way of legitimizing shoddy qualitative research (73). Finally, as has been already shared, the various advocates for Grounded Theory occasionally become engaged in procedural disputes, no doubt causing confusion to newcomers.

A second challenge is that many art and design students may see research as outside of their personal interests and professional career objectives. Under pressure to find immediate employment upon graduation, it is tempting for students to show more interest in those skills that produce visible and tangible outputs. Even within the liberal arts 
communities, rigorous research methods are often slow to be adopted among undergraduate students. Rick Roderick, Associate Professor of Communications at the University of Wisconsin reports from his experiences, "Although communication educators recognize the value of introducing research and scholarship to undergraduate students, there is likely to be resistance from students themselves" (75).

A third challenge facing research education is a general ambivalence towards formal research from art and design institutions themselves. This is perhaps linked to accreditation criteria that place a premium on studios hours and object making. The curious absence of Institutional Review Boards (IRB) in art and design education also indicates that human subject research is not yet a core concern in the design academy, despite the growing priority of human centricity in professional design (21). Art education scholar Mary Ann Stankiewicz, in a recent editorial laments that "research remains an unsettled issue in art education" (76]). While her concern was about the role and nature of research for the professional art educator, she recalls that this "open question" has been around for at least 50 years (77).

While considering these challenges in art and design education, it is important to note that the design industry is moving beyond its heritage of object-making to keep pace in a post-industrial knowledge economy. Accordingly, some design educators are asking if research is design's new signature pedagogy, and suggesting that "design is becoming more orientated towards design possibilities rather than producing objects..." $(78,79)$. Pushing the point, Dieter Lesage envisions that "One day we will be quite accustomed to the fact that a solo exhibition in a museum of contemporary arts won't be anything but the presentation of a doctorate in the arts" (4).

\section{Part 6: Conclusion: The future Is Interdisciplinary}

The primary intent of this paper has been to give an account of teaching Grounded Theory within the Art and Design college classroom, rather than an authoritative exposition of Grounded Theory methodology itself. This paper's review of the method should be regarded as elementary at best when compared to the extensive literature that already exists on the topic. As stated previously, Grounded Theory is not only a popular, but often contested method, across the broader literature base of sociology.

In practical terms, this broad acceptance of Grounded Theory can help artists and designers develop a robust research project that can be shared with interdisciplinary peers. Glaser has pointed out that, although Grounded Theory was conceived within sociology, the method's practitioners have represented a surprisingly diverse number of fields including "political science, social welfare, education, health education, educational sociology, public health, psychology, business administration, nursing, city and regional planning, and anthropology" (42). As such, it can help artists and designers to not only help formulate lucid social concepts for their practices, but to also relate their work to the global community of scholars and professionals from diverse epistemological traditions.

Helping build interdisciplinary and collaborative bridges is perhaps the most strategic aspiration for inviting Grounded Theory into arts education. Knowledge production, in addition to technical production, can be part of new social and market identities held by art and design students. Historically artists and designers have a heritage of being individualists and even iconoclasts; today, the question of whether artists and designers can also be collaborators is coming to the fore, as students in the 21 st century are facing far-reaching social challenges in ecological, commercial, educational, and political arenas. Art and design students hoping to contribute to these arenas can be encouraged and emboldened with cross-disciplinary research methods. Grounded Theory training can be a small but important step towards that end.

\section{Acknowledgements}

We'd like to give a special thanks to Tom Gattis, Alexis Schuknecht, Meagan Barrett, and Jeff Dickson for their help and support.

\section{REFERENCES}

[1] Alexander C. The origins of pattern theory: the future of the theory, and the generation of a living world. IEEE Softy IEEE Software. 1999; 16(5):71-82.

[2] Gregory SA. The design method: London: Butterworths; 1966.

[3] Cross N. Designedly ways of knowing. Basel: Birkha user; 2007.

[4] Lesage D. Who's afraid of artistic research? On measuring artistic research output. Art and Research: A Journal of Ideas, Contexts, and Methods; vol. 2. no. 2. 2009; http://www.artandresearch.org.uk/v2n2/pdfs/lesage.pdf; 2009

[5] Fuller RB, McHale J. World design science decade, 1965-1975; five two-year phases of a world retooling design proposed to the International Union of Architects for adoption by world architectural schools. Carbondale: World Resources Inventory; 1963.

[6] Dombois, F. Kunst und Forschung. Ein Kriterienkatalog und eine Replik dazu. Kunst-Bulletin 4. 2006:30-35.

[7] Klein J. Gegenworte 23 (2010) [Internet]. Eurozine -. 2014 [cited 2015Nov4]. Retrieved from 
http://www.eurozine.com/journals/gegenworte/issue/2010-0 7-30.html

[8] Krippendorff K. Design Research, an Oxymoron. Design Research Now: Essays and Selected Projects. 2007;

[9] Denzin NK, Lincoln YS. Handbook of qualitative research. Thousand Oaks, CA: Sage Publications; 2000.

[10] Nisbet RA. Sociology as an art form. New York: Oxford University Press; 1976.

[11] Denzin NK. The Qualitative Manifesto: A Call to Arms. Walnut Creek, CA: Left Coast Press; 2010.

[12] Rouch J. Ciné-Ethnography. Feld S, editor. University of Minnesota Press. 2003 [cited 2015Nov4]. Retrieved from: $\mathrm{http}: / /$ www.upress.umn.edu/book-division/books/cina-c-ethn ography

[13] Henley P. The adventure of the real Jean Rouch and the craft of ethnographic cinema. Chicago: University of Chicago Press; 2009

[14] Papanek V. Design for the real world: human ecology and social change. London: Thames and Hudson; 1985.

[15] Alexander C. The nature of order: an essay on the art of building and the nature of the Universe. Berkeley, CA: Center for Environmental Structure; 2002.

[16] Bailey C. Anthropology in Business and Industry: A Synopsis [Internet]. Bailey Work Play. 2009. Retrieved from: http://www.baileyworkplay.com/2009/10/anthropology-in-b usiness-and-industry-a-synopsis/

[17] Gablik S. Beyond the Rectangle, Out of the Frame; Art as Compassionate Action. The Reenchantment of Art. New York, NY: Thames and Hudson; 1991. p. 115-31.

[18] Ulrich Karl T., Eppinger Steven D. Product Design and Development. Chicago, IL. McGraw-Hill College; 1995

[19] Hanington Bruce., Martin Bella. Universal methods of design: 100 ways to research complex problems, develop innovative ideas, and design effective solutions. Beverly, MA: Rockport Publishers; 2012.

[20] Gilgun J. Grounded Theory as Open-Ended and Adaptable: Three Views (Current Issues in Qualitative Research Book 2) Kindle Edition [Internet]. Grounded Theory as Open-Ended and Adaptable: Three Views (Current Issues in Qualitative Research Book 2). 2011 [cited 2015Nov4]. Retrieved from: http://www.amazon.com/grounded-theory-open-ended-adapt able-qualitative-ebook/dp/b004m8s846

[21] Blauvelt A. Design's Ethnographic Turn. Design Observer. 2007. Retrieved from:http://designobserver.com/article.php? $\mathrm{id}=5467$

[22] Alexander C. The Origins of Pattern Theory [Internet]. IEEE. 1996 [cited 2015Nov4]. Retrieved from: http://www.patternlanguage.com/archive/ieee/ieeetext.htm

[23] Blomberg Jeanette, Giacomi Jean, et. al. Ethnographic Field Methods and Their Relation to Design. Participatory Design: Principles and Practices. Hilldale, NJ; 1993

[24] Wolcott Harry F. Writing up Qualitative Research: Getting Going. London, UK. Sage Publishing; 1990.

[25] Van Maanen John. Tales of the Field:On Writing Ethnography 2e. Chicago, IL. University of Chicago Press;
2011

[26] Lewis GH. Problems of life and mind first series: the foundations of a creed. Boston: J.R. Osgood; 1874.

[27] Wan PY-ze. Reframing the Social: Emergentist Systemism and Social Theory. Farnham: Ashgate; 2011.

[28] Wettersten John. From interview at IDEO Chicago, IL. 2014

[29] Chang Heewon. Autoethnography as Method: Developing Qualitative Inquiry. Left Coast Press; Walnut Creek, CA; 2008

[30] The World Bank. Services, etc., value added (\% of GDP) http://data.worldbank.org/indicator/NV.SRV.TETC.ZS; Washington DC. Accessed December 28, 2015.

[31] Parv. Explain the Goods-Services Continuum. Mumbai IN. 2012

http://www.bms.co.in/explain-the-goods-service-continuum/ retrieved 12282015

[32] Sakao Tomohiko, Lindahl Mattias. Introduction to Product/Service-System Design. New York, NY; Springer; 2009

[33] Jégou F., Gouache C., et. al. Development of Innovative Business Models for Product-Service Systems in an Urban Context of Sustainable Transition. http://issuu.com/strategic designscenarios/docs/pss_v3 english full quality interac/1? $\mathrm{e}=1860131 / 7392948$. Brussels, BG. 2014

[34] Borgdorff H. The Production of Knowledge in Artistic Research. The Routledge Companion to Research in the Arts. New York, NY; 2010

[35] Glaser Barney G., Strauss Anselm. The discovery of grounded theory: strategies for qualitative research. Chicago IL: Aldine Pub. Co.; 1967.

[36] Rolling Jr. JH. A Paradigm Analysis of Arts-based Research. Arts-based Research Primer. pp. 1-2. Pater Lang Publishing; New York NY2013

[37] Strauss AL, Corbin JM. Basics of qualitative research: grounded theory procedures and techniques. Newbury Park, CA: Sage Publications; 1990.

[38] Strauss AL, Corbin JM. Basics of qualitative research: techniques and procedures for developing grounded theory. Thousand Oaks: Sage Publications; 1998.

[39] Glaser BG. Emergence vs forcing: basics of grounded theory analysis. Emergence vs forcing: basics of grounded theory analysis. Mill Valley, CA: Sociology Press; 1992. p. 29.

[40] Kelle U. "Emergence" vs. "Forcing" of Empirical Data? A Crucial Problem of "Grounded Theory" Reconsidered [Internet]. Forum: Qualitative Social Research (Sozialforschung). 2005 [cited 2015Nov5]. Retrieved from: http://www.qualitative-research.net/index.php/fqs/article/vie $\mathrm{w} / 467 / 1000$

[41] Glaser BG. Getting Out of the Data: Grounded Theory Conceptualization. Mill Valley, CA: Sociology Press; 2011.

[42] Glaser BG. Theoretical sensitivity: advances in the methodology of grounded theory. Mill Valley, CA: Sociology Press; 1978.

[43] Andrews R. The Sage handbook of digital dissertations and theses. Los Angeles CA. SAGE; 2012. 
[44] Barone T, Eisner EW. Arts Based Research. Los Angeles, CA. SAGE; 2012.

[45] Charmaz K. Constructing grounded theory: a practical guide through qualitative analysis. London: Sage Publications; 2006.

[46] Strauss AL, Corbin JM. Basics of qualitative research: techniques and procedures for developing grounded theory. 3rd ed. Thousand Oaks: Sage Publications; 2007.

[47] Glaser B. Conceptualization and Linguistic Expression: Using Religious Poetry in ELT. Advances in Language and Literary Studies ALLS. 2002.

[48] Glaser BG. The Grounded Theory Perspective: Conceptualization Contrasted with Description. Mill Valley, CA: Sociology Press; 2001.

[49] Glaser BG. All is Data. The Grounded Theory Review. Vol. 6, No. 2. Mill Valley, CA: Sociology Press; 2007.http://groundedtheoryreview.com/2007/03/30/1194/ Retrieved 12282015

[50] Creswell JW. Research design: qualitative, quantitative, and mixed method approaches. Thousand Oaks, CA: Sage Publications; 2003.

[51] Konecki KT. Visual grounded theory: A methodological outline and examples from empirical work [Internet]. 2011 [cited 2015Nov4]. Retrieved from: http://hrcak.srce.hr/file/106256

[52] Cage J. Silence: lectures and writings. Middletown, CT: Wesleyan University Press; 1961.

[53] Ziller RC. Photographing the self: methods for observing personal orientations. Newbury Park, CA: Sage; 1990.

[54] Hahn C. Doing Qualitative Research Using Your Computer: A Practical Guide. Los Angeles: SAGE; 2008.

[55] Bringer J., Halley Johnson. Using Computer-assisted Qualitative Analysis Software to Develop a Grounded Theory Project. Field Methods. 2006; 245-66.

[56] Glaser BG. Memoing: A Vital Grounded Theory Procedure. Mill Valley, CA: Sociology Press; 2014.

[57] Charmaz K. Constructing grounded theory. London: Sage Publications; 2012.

[58] Saldaña Johnny, Miles MB. The Coding Manual for Qualitative Researchers Qualitative Data Analysis: A Methods Sourcebook. London: Sage Publications; 2013.

[59] Glaser, BG. with the assistance of Judith Holton. Remodeling Grounded Theory: Forum Qualitative Sozialforschung / Forum: Qualitative Social Research, 5(2), Art. 4, http://nbn-resolving.de/urn:nbn:de:0114-fqs040245. 2004, 2011

[60] Glaser B. The Literature Review in Grounded Theory [Internet]. YouTube. YouTube; 2010 [cited 2015Nov4]. Retrieved from:

https://www.youtube.com/watch?v=7s1kj0k3yhk

[61] Erwin K. Communicating the New: Methods to Shape and Accelerate Innovation. New York, NY; Wiley. 2013
[62] Huehls Frances. An Evening of Grounded Theory: Teaching Process through Demonstration and Simulation. The Qualitative Report Vol. 10. No. 2 Pg. 328; 2005

[63] Ausubel DP. The psychology of meaningful verbal learning. New York: Grune \& Stratton; 1963.

[64] Martin Roger C. Agile Software Development, Principles, Patterns, and Practices. New York NY. Pearson; 2002

[65] Cockburn A. Writing effective use cases. Boston: Addison-Wesley; 2001.

[66] Curedale R. Service Design: 250 Essential Methods. Topanga, CA: Design Community College Inc.; 2013.

[67] Greenbaum Joan. A Design of One's Own: Towards Participatory Design in the United States. Printed in Participatory Design: Principles and Practices. Hillsdale NJ: Lawrence Erlbaum Associates; 1993.

[68] Curedale R. Design research methods: 150 ways to inform design. Topanga, CA: Design Community College Inc.; 2013.

[69] Fendt Jacqueline, Sachs Wladimir. Grounded Theory Method in Management Research: Users' Perspectives. Organizational Research Methods, Vol. 11, No. 3. New York, NY: Sage Publications; 2008.

[70] Brassard M. The Memory Jogger Plus + Methuen, MA. 1989 pp. 17-39

[71] Krueger Richard A., Casey Mary Anne. Focus Groups: A Practical Guide for Applied Research. New York, NY. Sage Publishing; 2014

[72] Heller Steven. Writing and Research for Graphic Designers: A Designer's Manual to Strategic Communication and Presentation New York, NY. Rockpot Publishers; 2015

[73] Bryant A. Grounded Theory and Pragmatism: The Curious Case of Anselm Strauss [Internet]. Forum: Qualitative Social Research (Sozialforschung). 2009 [cited 2015Nov5]. Retrieved from:http://www.qualitative-research.net/index.ph $\mathrm{p} /$ fqs/article/view/1358/2850

[74] Allan G. A Critique of Using Grounded Theory as a Research Method. Electronic Journal of Business Research Methods. 2003;2(1):1-10.

[75] Roderick R. \& Dickmeyer L.. You're a Grounded Theorist for the Day: Teaching Students the Grounded Theory Approach. Printed in Communication Teacher. Vol. 24, no. 4. 2010

[76] Stankiewicz Mary Ann. Why Research in Art Education? Studies in Art Education: A Journal of Issues and Research in Art Education, Vol. 57, No. 1. Alexandria, VA: 2015. P. 1

[77] Housman Jerome J. Research in Art Education: 9th yearbook. Kutztown, PA: National Art Education Association; 1959. P. 3

[78] Tovey Mike. Design Pedagogy: Developments in Art and Design Education. Farnham, UK: Gower Pub Co; New edition; 2015

[79] Lloyd Peter. Educating Designers for Embedded Creativity. Collection vol. 4. www.collection.paris.edu. Paris FR: École Parsons à Paris; 2012 